\title{
Interprofessional collaborative care characteristics and the occurrence of bedside interprofessional rounds: a cross-sectional analysis
}

\author{
Jed D. Gonzalo ${ }^{1,5^{*}}$, Judy Himes², Brian McGillen ${ }^{5}$, Vicki Shifflet ${ }^{3}$ and Erik Lehman ${ }^{4}$
}

\begin{abstract}
Background: Interprofessional collaboration improves the quality of medical care, but integration into inpatient workflow has been limited. Identification of systems-based factors promoting or diminishing bedside interprofessional rounds (BIR), one method of interprofessional collaboration, is critical for potential improvements in collaboration in hospital settings. The objective of this study was to determine whether the percentage of bedside interprofessional rounds in 18 hospital-based clinical units is attributable to spatial, staffing, patient, or nursing perception characteristics.

Methods: A prospective, cross-sectional assessment of data obtained from nursing audits in one large academic medical center on a sampling of hospitalized pediatric and adult patients in 18 units from November 2012 to October 2013 was performed. The primary outcome was the percentage of bedside interprofessional rounds, defined as encounters including one attending-level physician and a nurse discussing the case at the patient's bedside. Logistic regression models were constructed with four covariate domains: (1) spatial characteristics (unit type, bed number, square feet per bed), (2) staffing characteristics (nurse-to-patient ratios, admitting services to unit), (3) patient-level characteristics (length of stay, severity of illness), and (4) nursing perceptions of collegiality, staffing, and use of rounding scripts.
\end{abstract}

Results: Of 29,173 patients assessed during 1241 audited unit-days, 21,493 patients received BIR (74\%, range 35-97 \%). Factors independently associated with increased occurrence of bedside interprofessional rounds were: intensive care unit (odds ratio 9.63, [Cl 5.30-17.42]), intermediate care unit (odds ratio 2.84, [Cl 1.37-5.87]), hospital length of stay 5-7 days (odds ratio 1.89, [Cl, 1.05-3.38]) and $>7$ days (odds ratio 2.27, [Cl, 1.28-4.02]), use of rounding script (odds ratio 2.20, [Cl 1.15-4.23]), and perceived provider/leadership support (odds ratio 3.25, [Cl 1.83-5.77]).

Conclusions: Variation of bedside interprofessional rounds was more attributable to unit type and perceived support rather than spatial or relationship characteristics amongst providers. Strategies for transforming the value of hospital care may require a reconfiguration of care delivery toward more integrated practice units.

Keywords: Interprofessional collaborative care, Relational coordination, Team-based care, Health services research, Patient-centered care, Hospital-based medicine, Quality improvement

\footnotetext{
* Correspondence: jgonzalo@hmc.psu.edu; jedgonzalo@hotmail.com

${ }^{1}$ Medicine and Public Health Sciences, Health Systems Education,

Pennsylvania State University College of Medicine, Hershey, PA, USA

${ }^{5}$ Division of General Internal Medicine, Penn State Hershey Medical

Center - HO34, 500 University Drive, Hershey, PA 17033, USA

Full list of author information is available at the end of the article
} 


\section{Background}

Interprofessional collaborative care (IPCC) is the process through which different professional groups work together to improve healthcare quality [1-4]. Providers of different professions working as a team promotes improved communication, coordination of care, and patient-centered shared-decision making $[5,6]$. Given the emerging evidence of the positive impact of IPCC on outcomes, work processes integrating IPCC models into healthcare delivery is a national health policy focus specifically in the proposed changes in the Affordable Care Act [1, 2, 7, 8]. Although there is a need to accelerate and transform healthcare delivery to be more team-based and patient centered, implementation of IPCC methods in hospitalbased units has not been well studied [9].

Factors promoting care coordination and teamwork in hospital-based units include routines, such as treatment pathways, individuals serving boundary-spanning roles, and team meetings [10]. Hospitalized patients' care involves mutual relationships, collaboration, and decision-making between all healthcare providers and patients, highlighting the need for IPCC methods to improve quality [1]. Bedside interprofessional rounds (BIR) including both physicians and nursing staff are a primary method of promoting collaboration in hospitalbased settings [4, 11-13]. However, studies investigating the occurrence of BIR in medicine, pediatrics, and intensive care units demonstrate a wide variation in frequency from 1-80 \% [14-17]. To our knowledge, no studies have investigated the incidence of BIR across different hospitalbased units, or identified unit-level collaboration-related characteristics associated with BIR. Identification of systems-based factors promoting or diminishing the frequency of BIR is vital for providing potential improvement targets for this patient-centered activity.

Starting in 2012, our institution introduced a new quality metric related to BIR, defined as nurses and physicians working together at the bedside during rounds. In this study, we sought to: (1) examine the percentage of patients receiving BIR in 18 different units within our hospital, and, (2) determine whether the percentage of BIR is attributable to four categories of variables, including spatial, staffing, patient, and nursing perception characteristics. We hypothesized intensive care unit settings, higher nurse-to-patient ratios, and smaller unit sizes would be associated with a higher percentage of BIR.

\section{Methods}

\section{Study design}

Following a hospital-wide initiative to increase BIR, from November 2012-October 2013, we performed a prospective cross-sectional assessment of data obtained from nursing audits completed during $\geq 5$ days per month in 18 hospital units. The Institutional Review Board determined this study did not meet the definition of human subjects research and therefore more formal submission and approval was not required.

\section{Study setting}

The study was conducted at a 501-bed university-based acute care hospital in central Pennsylvania. Our hospital provides a full spectrum of medical and surgical care for pediatric and adult patients. In 2012, our hospital leadership sought to improve IPCC between providers and patients. The primary expectation was for all frontline teams to perform BIR on $\geq 80 \%$ of patients per day in each unit. To obtain mutual understanding amongst providers and set clear expectations for continual assessment, an a priori definition was established for BIR: "encounters that include at least one attendinglevel physician (from the primary team) and nurse discussing the case at the patient's bedside."

\section{Study outcomes}

The primary outcome was the percentage of BIR occurring in each unit. For the covariates, since the literature has not identified specific categories of system or collaboration-related factors associated with BIR, we undertook an exploratory approach to variable selection. Through research team meetings, informal interviews, a literature review, and our work on medicinebased BIR, we developed four categories of variables hypothesized to affect BIR (Tables 1 and 2) [18, 19]. First, to address the spatial-related factors that may promote IPCC, we selected several variables, including unit type (acute, intermediate, intensive care), number of beds in unit, and square feet in unit per bed. Staffing and service factors included nurse-to-patient ratios and number of admitting services in unit per bed, calculated by dividing the number of different admitting services admitting $\geq 5$ patients to the unit during the study period by number of unit beds. This variable was developed to reflect the degree of team variability in each unit. Patient characteristics included hospital length-of-stay for patients admitted to each unit, and severity of illness measured by the APR-DRG, a variable derived from billing data [20]. Nursing perceptions of nurse-physician collegiality, staffing adequacy, provider support, and use of a BIR script were evaluated.

\section{Data sources and collection}

To monitor the success of the hospital-wide BIR initiative, each unit's nurse manager/charge nurse performed "audits" on $\geq 5$ randomly selected days each month during the 12-month period. The nursing-audit process involved asking each bedside nurse to report how many of his/her patients received BIR according to the 
Table 1 Characteristics of hospital-based units $(n=18)$ in the Penn State Hershey Medical Center

\begin{tabular}{|c|c|c|c|c|c|c|c|c|c|c|c|}
\hline \multirow[t]{2}{*}{ Unit } & \multicolumn{3}{|c|}{ Spatial Characteristics } & \multicolumn{2}{|c|}{ Staffing/Service } & \multicolumn{2}{|c|}{$\begin{array}{l}\text { Patient } \\
\text { Characteristics }\end{array}$} & \multicolumn{4}{|c|}{ Nursing Perceptions } \\
\hline & $\begin{array}{l}\text { Unit } \\
\text { Type }^{\text {a }}\end{array}$ & $\begin{array}{l}\text { No. of } \\
\text { Beds }\end{array}$ & $\begin{array}{l}\text { Sq. Ft } \\
\text { per bed }\end{array}$ & $\begin{array}{l}\text { Nurse- } \\
\text { patient ratio }\end{array}$ & $\begin{array}{l}\text { Admitting Services } \\
\text { per bed }^{\mathrm{b}}\end{array}$ & $\begin{array}{l}\text { Length } \\
\text { of Stay }\end{array}$ & $\begin{array}{l}\text { Severity } \\
\text { of Illness }\end{array}$ & Collegiality $^{d}$ & Staffing $^{d}$ & $\begin{array}{l}\text { Rounding } \\
\text { Script }^{e}\end{array}$ & $\begin{array}{l}\text { Support } \\
\text { Score }^{f}\end{array}$ \\
\hline Pediatric Intensive Care & 3 & 18 & 878 & $1: 1.5$ & 0.22 & 8.95 & 2.83 & 2.99 & 1.95 & 7 & 21 \\
\hline Neonatal Intensive Care & 3 & 31 & 303 & $1: 2$ & 0.03 & 25.27 & 2.79 & 2.49 & 2.66 & 5 & 17 \\
\hline Surgical Intensive Care & 3 & 30 & 553 & $1: 2$ & 0.63 & 7.96 & 2.98 & 2.48 & 2.33 & 7 & 19 \\
\hline Medical Intensive Care & 3 & 16 & 597 & $1: 2$ & 0.38 & 8.62 & 3.33 & 2.95 & 2.90 & 4 & 18 \\
\hline Neurology & $1,2,3$ & 35 & 672 & $1: 2.5$ & 0.17 & 5.75 & 2.47 & 3.11 & 2.73 & 3 & 16 \\
\hline $\begin{array}{l}\text { Heart and Vascular } \\
\text { Cardiac Care }\end{array}$ & 3 & 15 & 666 & $1: 2$ & 0.47 & 7.84 & 2.73 & 2.87 & 3.00 & 2 & 13 \\
\hline Cancer Institute & 1,2 & 39 & 435 & $1: 4$ & 0.33 & 5.15 & 2.28 & 2.91 & 2.64 & 3 & 17 \\
\hline $\begin{array}{l}\text { Heart and Vascular } \\
\text { Progressive Care }\end{array}$ & 1,2 & 24 & 398 & $1: 3.5$ & 0.25 & 5.56 & 2.37 & 2.84 & 3.12 & 5 & 18 \\
\hline $\begin{array}{l}\text { Pediatric Hematology- } \\
\text { Oncology Service }\end{array}$ & 1 & 16 & 987 & $1: 2.5$ & 0.38 & 6.18 & 2.19 & 3.15 & 2.88 & 6 & 17 \\
\hline Women's Health & 1 & 24 & 203 & $1: 4.5$ & 0.17 & 6.10 & 1.42 & 3.30 & 2.68 & 6 & 21 \\
\hline $\begin{array}{l}\text { Pediatric } \\
\text { Intermediate Care }\end{array}$ & 2 & 17 & 872 & $1: 2.5$ & 0.59 & 3.97 & 2.20 & 3.01 & 2.53 & 4 & 15 \\
\hline Pediatric Acute Care & 1 & 36 & 411 & $1: 3.5$ & 0.28 & 3.10 & 1.84 & 2.99 & 2.72 & 5 & 18 \\
\hline $\begin{array}{l}\text { Medical } \\
\text { Intermediate Care }\end{array}$ & 2 & 20 & 470 & $1: 3$ & 0.30 & 7.09 & 2.74 & 2.81 & 2.42 & 1 & 16 \\
\hline General Surgery & 1 & 18 & 496 & $1: 4.5$ & 0.61 & 3.54 & 2.11 & 3.10 & 2.54 & 3 & 19 \\
\hline $\begin{array}{l}\text { Internal/Family } \\
\text { Medicine }\end{array}$ & 1 & 44 & 385 & $1: 4$ & 0.20 & 4.45 & 2.50 & 3.17 & 2.77 & 2 & 17 \\
\hline $\begin{array}{l}\text { General Surgery/ } \\
\text { Neurology }\end{array}$ & 1 & 44 & 385 & $1: 4.5$ & 0.34 & 4.02 & 2.21 & 2.87 & 2.48 & 1 & 12 \\
\hline General Surgery & 1 & 42 & 404 & $1: 4.5$ & 0.50 & 4.60 & 2.36 & 2.78 & 2.55 & 4 & 16 \\
\hline Flex/Observation & 1 & 14 & 765 & $1: 4.5$ & 0.93 & 5.01 & 2.44 & - & - & 3 & 16 \\
\hline
\end{tabular}

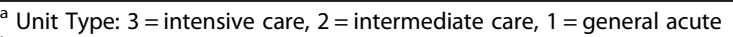

b Number of different services admitting $\geq 5$ patients to unit in one-year period/number of unit beds

c Derived from billing data (APR-DRG value)

d Scores obtained from Collegial Nurse-Physician Relations/Staffing/Resource Adequacy domain from Practice Environment of the Nursing Work Index; flex/observation had a "float" pool of nurses, thereby could not receive a survey; responses $4=$ strongly agree, $3=$ agree, $2=$ disagree, $1=$ strongly disagree

e Reported by units' nursing leadership on a 1-7 scale ( $1=$ not at all, $7=$ a great extent)

f Summation score from 3 domains on a 1-7 scale ( $1=$ not at all, $7=$ a great extent), max score 21

definition on that day. At month's end, each unit submitted tallies to the Department of Nursing, which were posted on the hospital's Quality Dashboard.

Covariates were obtained from several sources. For spatial characteristics, we obtained and analyzed the floor plans for each unit. For patient- and servicelevel characteristics, we used our hospital's clinical data warehouse to acquire the number of admitting services to the unit per bed, length-of-stay, and severity of illness. For nursing perceptions of nurse-physician relations and staffing adequacy, we used scores from the National Database of Nursing Quality Indicators Practice Environment Scale of the Nursing Work Index (PESNWI) in the domain of Collegial Nurse-Physician Relations (three items) and Staffing/Resource Adequacy (four items) obtained during the study period (Appendix 1). The "flex/observation" unit was not included in the PES-
NWI survey because nurses were from a float pool originating from several units. For nurse-to-patient ratios, perceived support, and use of a BIR script, we administered a paper-based survey in May 2014 to each unit's nurse manager. Questions related to unit characteristics and included quantitative and Likert-scale questions (Additional file 1).

\section{Data analysis}

Descriptive statistics were used to report characteristics of each unit, patient census, and BIR frequency. The primary outcome (percentage of BIR) was calculated as the sum of all patients receiving BIR divided by the sum of the unit's census from all recorded audits for each day and multiplied by $100 \%$. Percent BIR was not normally distributed and was difficult to analyze with parametric analysis. Therefore, we stratified percent 
Table 2 Frequency of patients receiving bedside interprofessional rounds by unit $(n=18)$ at the Penn State Hershey Medical Center (Nov. 2012-Dec. 2013)

\begin{tabular}{|c|c|c|c|c|c|}
\hline Unit & No. of Days ${ }^{a}$ & Total Patients & Ave. census/day & $\begin{array}{l}\text { No. of Patients } \\
\text { Receiving BIR }\end{array}$ & Frequency of BIR \\
\hline Pediatric Intensive Care & 63 & 755 & 11.98 & 733 & 0.97 \\
\hline Neonatal Intensive Care & 59 & 1812 & 30.71 & 1732 & 0.96 \\
\hline Surgical Intensive Care & 66 & 1622 & 24.58 & 1546 & 0.95 \\
\hline Medical Intensive Care & 72 & 1091 & 15.15 & 1003 & 0.92 \\
\hline Neurology & 72 & 2192 & 30.44 & 1784 & 0.81 \\
\hline Heart and Vascular Cardiac Care & 66 & 1806 & 27.36 & 1465 & 0.81 \\
\hline Cancer Institute & 69 & 2380 & 34.49 & 1917 & 0.81 \\
\hline Heart and Vascular Progressive Care & 69 & 1623 & 23.52 & 1294 & 0.80 \\
\hline Pediatric Hematology-Oncology Service & 69 & 1066 & 15.45 & 844 & 0.79 \\
\hline Women's Health & 71 & 1569 & 22.10 & 1224 & 0.78 \\
\hline Pediatric Intermediate Care & 80 & 1148 & 14.35 & 861 & 0.75 \\
\hline Pediatric Acute Care & 77 & 1358 & 17.64 & 1015 & 0.75 \\
\hline Medical Intermediate Care & 70 & 1175 & 16.79 & 862 & 0.73 \\
\hline General Surgery & 71 & 925 & 13.03 & 653 & 0.71 \\
\hline Internal/Family Medicine & 71 & 3065 & 43.17 & 2004 & 0.65 \\
\hline General Surgery/Neurology & 63 & 2553 & 40.52 & 1214 & 0.48 \\
\hline General Surgery & 67 & 2708 & 40.42 & 1227 & 0.45 \\
\hline Flex/Observation & 66 & 325 & 4.92 & 115 & 0.35 \\
\hline
\end{tabular}

${ }^{a}$ Number of days during the study when audits performed

BIR into two groups based around the median: high $(\geq 80 \%)$ and low $(<80 \%)$ to keep the bias low; based on prior studies, this cut off also served as an ideal and reasonable target for BIR $[4,21]$. Because our binary outcome variable was measured repeatedly over time within each unit, a generalized estimating equations (GEE) model was used to identify predictors of the main outcome. Odds ratios were used to quantify the magnitude and direction of significant associations. A multivariable GEE model with all significant predictors $(p<0.05)$ from bivariate analysis was used to determine if each predictor maintained its significance when adjusted for the others. A check for multicollinearity between predictor variables was made using variance inflation factors (VIF) statistics from linear regression prior to applying the multivariable model. All VIF statistics for variables included in the model were below 5 . The final reduced model fit for the significant predictor variables was checked against the starting full model that included all predictor variables using QIC statistics for GEE model comparison, and the QIC was higher in the model including only the significant predictor variables. Data were analyzed using SAS 9.4 (Cary, NC).

\section{Results}

\section{Characteristics of units and collaboration factors}

Of 18 units, six were intensive-care units (ICU), four were intermediate care units, and eight were acute care units (Table 1). Average number of beds per unit was 27 (range 14-44), with a mean 549 square feet per bed (range 203-987). Nurse-to-patient ratio mean was 1 to 3.2 (range 1.5-4.5). Patients' mean length-ofstay was 6.8 days (range 3.1-25.3) and severity of illness was 2.43 (range 1.4-3.3).

\section{Bedside interprofessional rounds}

During the study period, 29,173 patients (mean 23.5 patients per unit per day) were assessed during 1241 audited unit-days, with 21,493 patients receiving BIR (74 \%, range $35-97 \%$, Table 2).

\section{Factors associated with bedside interprofessional rounds}

Factors independently associated with increased occurrence of BIR were intensive care unit (OR 9.63, [CI 5.3017.42], vs. acute-care), intermediate care unit (OR 2.84, [CI 1.37-5.87], vs. acute-care), length-of-stay 5-7 days (OR 1.89, [CI, 1.05-3.38], vs. $<5$ days) and $>7$ days (OR 2.27 , [CI, 1.28-4.02], vs. $<5$ days), use of rounding script (OR 2.20, [CI 1.15-4.23], score $\geq 4$ vs. $<4$ ), and perceived provider/leadership support (OR 3.25, [CI 1.83-5.77], score $\geq 17$ vs. $<17$, Table 3 ). Number of beds, square feet in unit and per bed, admitting services per bed, nursepatient ratios, nurse-physician collegiality score, and severity of illness showed no associations with BIR. 
Table 3 Associations between spatial, staffing, patient, and nursing perception variables and frequency of bedside interprofessional rounds in 18 hospital-based units (total $n=1241$ )

\begin{tabular}{|c|c|c|c|}
\hline Variable - n (\%) & $\begin{array}{l}\text { Bedside Interprofessional } \\
\text { Rounds, } \geq 80 \%(n=669)\end{array}$ & Unadjusted OR (95% Cl) & Adjusted OR (95\% Cl) \\
\hline \multicolumn{4}{|l|}{ Spatial Characteristics } \\
\hline \multicolumn{4}{|l|}{ Unit type: } \\
\hline General care & $172(25.7)$ & 1 & 1 \\
\hline Intermediate care & $158(23.6)$ & $2.83(1.19-6.73)$ & $2.84(1.37-5.87)$ \\
\hline Intensive care & $339(50.7)$ & $13.65(4.30-43.34)$ & $9.63(5.30-17.42)$ \\
\hline \multicolumn{4}{|l|}{ Number of unit beds: } \\
\hline$<19$ & $285(42.6)$ & 1 & \\
\hline $19-35$ & $278(41.6)$ & $1.57(0.50-4.88)$ & \\
\hline$>35$ & $106(15.8)$ & $0.30(0.07-1.19)$ & \\
\hline \multicolumn{4}{|l|}{ Square feet per bed: } \\
\hline$<410$ & $160(23.9)$ & 1 & \\
\hline $410-600$ & $268(40.1)$ & $2.54(0.61-10.57)$ & \\
\hline$>600$ & $241(36.0)$ & $2.05(0.53-8.01)$ & \\
\hline \multicolumn{4}{|l|}{ Staffing/Service } \\
\hline \multicolumn{4}{|l|}{ Nurse-patient ratio: } \\
\hline$>1: 3$ & $228(34.1)$ & 1 & 1 \\
\hline$\leq 1: 3$ & $441(65.9)$ & $4.71(1.73-12.85)$ & $1.14(0.64-2.03)$ \\
\hline \multicolumn{4}{|c|}{ Number of admitting services in unit/bed: ${ }^{a}$} \\
\hline$<0.35$ & $370(55.3)$ & 1 & \\
\hline$\geq 0.35$ & $299(44.7)$ & $0.96(0.32-2.86)$ & \\
\hline \multicolumn{4}{|l|}{ Weekday } \\
\hline No & $143(21.4)$ & 1 & \\
\hline Yes & $526(78.6)$ & $1.19(0.94-1.51)$ & \\
\hline \multicolumn{4}{|l|}{ Patient Characteristics } \\
\hline \multicolumn{4}{|c|}{ Hospital length of stay for patients admitted to unit: } \\
\hline$<5$ days & $114(17.0)$ & 1 & 1 \\
\hline 5-7 days & $235(35.1)$ & $3.75(1.53-9.21)$ & $1.89(1.05-3.38)$ \\
\hline$>7$ days & $320(47.8)$ & $12.82(3.25-50.52)$ & $2.27(1.28-4.02)$ \\
\hline \multicolumn{4}{|c|}{ Severity of illness (APR-DRG): } \\
\hline$<2.4$ & $285(42.6)$ & 1 & \\
\hline$\geq 2.4$ & $384(57.4)$ & $2.27(0.75-6.82)$ & \\
\hline \multicolumn{4}{|l|}{ Nursing Perceptions } \\
\hline \multicolumn{4}{|c|}{ Nurse-physician collegial score: ${ }^{b}$} \\
\hline$<2.95$ & $302(46.1)$ & 1 & \\
\hline$\geq 2.95$ & $353(53.9)$ & $0.92(0.29-2.90)$ & \\
\hline \multicolumn{4}{|c|}{ Staffing and resource adequacy: } \\
\hline$<2.67$ & 337 (51.5) & 1 & \\
\hline$\geq 2.67$ & $318(48.6)$ & $1.00(0.33-3.02)$ & \\
\hline \multicolumn{4}{|l|}{ BIR script score:c } \\
\hline$<4$ & $214(32.0)$ & 1 & 1 \\
\hline$\geq 4$ & $455(68.0)$ & $3.18(1.11-9.13)$ & $2.20(1.15-4.23)$ \\
\hline
\end{tabular}


Table 3 Associations between spatial, staffing, patient, and nursing perception variables and frequency of bedside interprofessional rounds in 18 hospital-based units (total $n=1241$ ) (Continued)
BIR support score: ${ }^{d}$
$<17$
$182(27.2)$
1
1
$\geq 17$
$487(72.8)$
$3.24(1.17-8.97)$
$3.25(1.83-5.77)$
${ }^{a}$ Number of different services admitting $\geq 5$ patients to unit in a one-year period/unit beds
${ }^{\mathrm{b}}$ Scores obtained from Collegial Nurse-Physician Relations/Staffing/Resource Adequacy from Practice Environment of the Nursing Work Index (PES-NWI); responses
4 = strongly agree, 3 = agree, 2 = disagree, 1 = strongly disagree
'Reported by units' nursing leadership on a 1-7 scale $(1=$ not at all, $7=$ a great extent)
${ }^{\mathrm{d}}$ Summation score from 3 domains on a 1-7 scale ( $1=$ not at all, $7=$ a great extent), max score 21
${ }^{\mathrm{e}}$ Adjusted for other significant variables in Table 3

\section{Discussion}

In our hospital-based units during the one-year study period, frequency of BIR exceeded $70 \%$, with higher frequencies occurring in ICUs than intermediate or acutecare units. Additional factors associated with BIR were longer length-of-stay for patients admitted to the unit, and nursing leaderships' perceived support by providers and use of a BIR script; besides unit type, spatial characteristics were not associated with BIR. These results advance our understanding about factors impacting the occurrence of BIR in hospital units, and highlight potential barriers hindering ideal patient-centered care for all admitted patients. Awareness of benefits for IPCC is increasing, and potentially will become more integrated into quality performance measures. As a result, IPCC may become more widely used in models of reimbursement for hospitals $[8,22]$. Therefore, formal investigations into IPCC processes are required to inform improvement, and offer a theoretical model for informing the redesign of more integrated, hospital-based units achieving higher value.

In considering these results, two issues are critical to the discussion of BIR. First, in the context of "rounds," IPCC occurring at the bedside is relatively new to the literature. The traditional method of "bedside rounds," or physician teams rounding at the bedside, has been identified as a patient-centered method for education and care delivery [21, 23-25]. Numerous studies have investigated physician-based bedside rounds in several specialties, including pediatrics, internal medicine, and surgery $[14,26]$. These studies highlight that bedside rounds occur at an incidence of $<50 \%$ of all encounters, and $<20 \%$ of total rounding time [16, 17, 27-29]. However, integration of nurses or healthcare professionals with physicians at the bedside is less studied. Structured interdisciplinary bedside rounds (BIR using a script) and multidisciplinary rounds (interprofessional rounds in a conference room) are two forms of interprofessional rounds, however these concepts either have not been evaluated or do not occur at the bedside, respectively [30-32]. As described in our prior work on the medicine service, BIR occurred in two-thirds of patients, with higher frequencies occurring in intermediate care units (vs. acute-care), with more senior residents and less experienced attending physicians, during weekdays, and lower team census sizes [4]. This study expands on these concepts by assessing BIR not only in one unit or service line but rather in numerous hospital-based units, which, to our knowledge, has not previously been described.

Second, regardless of the type of rounds, the focus in the literature is on the service-line spanning several units rather than the clinical unit providing care for patients assigned to multiple service lines. Although some ICUs may be closed units, most hospital-based units care for patients assigned to a blend of service lines (e.g. medicine, surgical subspecialties) [33]. Individual units have nurses caring for patients admitted to the unit, however other provider groups encompass a highly variable array of physicians, mid-level providers, and allied health professionals. Most of these providers divide their patient care across several units. This provider "migration" creates challenges for optimal patient-centered IPCC, as each unit has different providers, processes, and culture [18, 34]. Prior research on IPCC suggests a general dichotomy between nurses, who tend to be "collectivist" and systems-driven, as compared to physicians who are more "individualists" and autonomy-driven, a schism that may be exacerbated by physician migration between units [35]. Complexities of these systems-, provider-, and team-based factors must be recognized by hospital leadership, providers, and researchers to allow focused consideration into and identification of unitlevel (and not only provider-team) factors promoting or diminishing BIR.

Bedside interprofessional rounds occurred far more frequently in ICUs, suggesting characteristics of these units are conducive to BIR. Past work has identified that in medicine service lines, more intermediate-care unit patients receive BIR compared to acute-care units, and physician-based team rounds encounter challenges with geographic dispersion of patients in different units $[4,19,36]$. Our prior work raised the question of the potential frequency of patients who receive BIR, suggesting that for medicine-based units, the maximum is $<70 \%$ [4]. Similarly, these results suggest that in units with higher patient-to-nurse ratios 
and number of admitting services per bed, a significant proportion of patients do not receive BIR.

Collectively, these findings raise the question of how hospital-based units can optimize value by achieving best outcomes at lower costs. With the wide variation of BIR in our hospital, inasmuch as these results are generalizable to other hospitals, the value transformation for hospitalized patients may require a change in the way providers are organized to deliver care [37]. As proposed by Porter and Lee in their work regarding strategies to promote the value transformation, the reorganization of care delivery into Integrated Practice Units (IPUs) potentially can allow frontline providers to collaborate towards a common end and coordinate care most efficiently [37, 38]. Aligning inpatient units toward IPUs, as our results suggest, initially may require an increase in closed units and geographic co-localization of patients [39]. Without such changes, core principles of team-base healthcare delivery and relational coordination, including shared goals, clear roles, and trust, are limited by fragmentation in current processes [10, 40, 41]. These are just two of several potential factors that may promote patient-centered BIR, and high-leverage areas for systems redesign. Patient co-localization by service and provider groups would require extensive changes (e.g. maintaining high census numbers, efficient emergency department throughput) that may prove difficult to achieve [33].

Investigations of collaboration factors promoting optimal work have been performed in management, business and sociology, but less in healthcare [42-45]. Collaboration theory has identified the determinants of successful collaboration within healthcare settings, which includes systemic factors, the social, cultural, and educational systems, interactional determinants and interpersonal relationships, and notably, organizational determinants [46-48]. These organizational determinants include organizational structure, administrative support, team resources, and coordination mechanisms, and suggest factors such as space and policies ensuring team-based meetings to enhance communication promote group processes necessary for collaboration and high levels of teamwork [45, 46, 49]. For example, Prescott and Bowen identified that smaller units may be more conducive to nursephysician relationships as these groups of providers are closer in physical proximity, thereby promoting collaboration [48]. Top qualities of workplace settings impacting team performance are the workplace's ability to support distraction-free individual work, impromptu interactions, and informal and formal encounters [45, 50]. Based on these data and our prior experience providing care in hospital-based settings, we hypothesized units with greater square footage and bed number (inverse), and nursingperceived collegiality and staffing/resource adequacy scores (direct) would be related to BIR, we found no association. The reason for these findings may be that variables were not sensitive enough to detect appropriate associations. In addition to available educational efforts to promote hospital-based IPCC, the identification of variables associated with IPCC are required to guide improvement efforts [3]. Ultimately, the development of a reliable tool to assess a unit's optimal balance of collaboration characteristics is critical for quality improvement efforts to optimize workflow, coordination, and IPCC in these clinical microsystems [51]. Spatial setting features, their effect on face-to-face interaction and collaborative care processes, and robust assessments of interprofessional collaboration content and quality are necessary in subsequent research to inform the proposed collaboration instrument.

There are several limitations to our study. First, data were obtained from a subset of patients during the study period, and these patients may have had a different casemix index compared to patients cared for in the unit during unmeasured days, which potentially limits the accuracy of the results. However, this near-time data collection method, also used in our prior work, was resource intensive and diminishes several biases inherent in remote recall $[52,53]$. Second, since our institutional goals were related to BIR benchmarks, nursing audits were susceptible to social desirability bias, potentially overestimating BIR frequency. Next, this study was only performed at one academic medical center, limiting the generalizability to other settings, particularly community or non-academic hospitals. Due to technical limitations, several variables were limited in scope. For example, although we used hospital length-of-stay for patients initially admitted to the unit, we could not accurately capture the patient's length-of-stay within individual units, which is likely a more sensitive variable for IPCC. Given the service-line specificity of Hospital Consumer Assessment of Healthcare Providers and Systems surveys and the mixed nature of our units, we were unable to accurately investigate this relationship. Lastly, these data are from 2012-2013, and given rapid changes to care processes in hospital settings, these findings may be less applicable to current-day settings.

\section{Conclusions}

In this study, BIR frequency was highly variable, ranging from $35-97 \%$. Factors predicting increased occurrence of BIR were ICUs, hospital length-of-stay for patients admitted to the unit, and nursing leaderships' perceived support by providers and use of a BIR script. These findings highlight both non-modifiable and modifiable collaboration variables to optimize patient-centered, IPCC in hospitalbased units. Future efforts will need to address additional variables associated with this model of IPCC. 


\section{Appendix 1}

2013 National Database of Nursing Quality Indicators (NDNQI) RN Survey with Practice Environment Scale`

Description: The Nursing Quality Indicators used in this study, including "staffing and resource adequacy" and "collegial nurse-physician relations," are shown in Appendix 1.

For each item, please indicate the extent to which you agree that the item is PRESENT IN YOUR CURRENT JOB (all response options: strongly agree, agree, disagree, strongly disagree).

\section{Staffing and resource adequacy}

1. Adequate support services allow me to spend time with my patients

2. Enough time and opportunity to discuss patient care problems with other nurses

3. Enough registered nurses to provide quality patient care.

4. Enough staff to get the work done.

\section{Collegial nurse-physician relations}

1. Physicians and nurses have good working relationships

2. A lot of team work between nurses and physicians.

3. Collaboration (joint practice) between nurses and physicians.

\section{Additional file}

Additional file 1: Nursing Leadership Survey - Bedside Interprofessional Rounds (RN-MD rounding). The Nursing Leadership Survey items used in this study, including characteristics of the nursing unit and perceptions of nurse leadership regarding bedside nurse-physician rounds, are shown in Additional file 1. (DOCX $32 \mathrm{~kb}$ )

\section{Acknowledgements}

The authors would like to thank Ms. Kristine A. Reynolds, Dr. Thomas Abendroth, and Mr. Frendy Glasser for their assistance with data acquisition, Dr. Eugene Beyt for his review and critique of the manuscript, and the nursing staff, nursing leadership, and physicians at the Penn State Hershey Medical Center for their dedication to patient-centered care.

\section{Funding}

None.

\section{Availability of data and materials}

The datasets supporting the conclusions of this article are available upon requests to the first author (Jed Gonzalo, jgonzalo@hmc.psu.edu).

\section{Authors' contributions}

The idea for the study and study design was developed by JDG, BM, and EL. VS and JH assisted with data collection and collation. JDG, VS, JH, and EL were involved with the original conceptualization of the study design. All authors assisted in the analysis and interpretation of data, and contributed to the drafting and critical revision of the paper. All authors approved the final manuscript for publication and have agreed to be accountable for all aspects of the work

\section{Competing interests}

The authors declare that they have no competing interests.

\section{Consent for publication}

Not applicable.

\section{Ethics approval and consent to participate}

This project (including the collection of nursing audits and clinical data variables) was approved by the Penn State College of Medicine Institutional Review Board as non-human subjects research (STUDY00001381). The need for consent related to the nursing audits was waived by the IRB.

\section{Author details}

${ }^{1}$ Medicine and Public Health Sciences, Health Systems Education, Pennsylvania State University College of Medicine, Hershey, PA, USA. ${ }^{2}$ Nursing Medical Services, Neuroscience, and Cancer Institute, Penn State Hershey Medical Center, Hershey, PA, USA. ${ }^{3}$ General Medicine Acute Care Unit, Penn State Hershey Medical Center, Hershey, PA, USA. ${ }^{4}$ Public Health Sciences, Pennsylvania State University College of Medicine, Hershey, PA, USA. ${ }^{5}$ Division of General Internal Medicine, Penn State Hershey Medical Center - HO34, 500 University Drive, Hershey, PA 17033, USA.

Received: 25 November 2015 Accepted: 25 August 2016

Published online: 01 September 2016

\section{References}

1. Zwarenstein M, Goldman J, Reeves S. Interprofessional collaboration: effects of practice-based interventions on professional practice and healthcare outcomes. Cochrane Database Syst Rev. 2009;3:CD000072.

2. Kim MM, Barnato AE, Angus DC, Fleisher LA, Kahn JM. The effect of multidisciplinary care teams on intensive care unit mortality. Arch Intern Med. 2010;170(4):369-76

3. Reeves S, Zwarenstein M, Goldman J, et al. Interprofessional education: effects on professional practice and health care outcomes. Cochrane Database Syst Rev. 2008;1:CD002213.

4. Gonzalo JD, Wolpaw DR, Lehman E, Chuang CH. Patient-centered interprofessional collaborative care: factors associated with bedside interprofessional rounds. J Gen Intern Med. 2014;29(7):1040-7.

5. Butcher L. Teamswork! Hosp Health Netw. 2012;86(3):24-7. 21.

6. Kohn LT, Corrigan J, Donaldson MS. To err is human : building a safer health system. Washington, D.C.: National Academy Press; 2000.

7. Institute of Medicine (U.S.) Committee on Quality of Health Care in America. Crossing the quality chasm : a new health system for the 21st century. Washington, D.C.: National Academy Press; 2001.

8. Kaboli PJ, Hoth AB, McClimon BJ, Schnipper JL. Clinical pharmacists and inpatient medical care: a systematic review. Arch Intern Med. 2006;166(9): 955-64.

9. Paradis $\mathrm{E}$, Reeves $\mathrm{S}$. Key trends in interprofessional research: a macrosociological analysis from 1970 to 2010. J Interprof Care. 2013;27(2): $113-22$

10. Gittell JH, Godfrey M, Thistlethwaite J. Interprofessional collaborative practice and relational coordination: improving healthcare through relationships. J Interprof Care. 2013;27(3):210-3.

11. Paradis $E$, Reeves $S$, Leslie $M$, et al. Exploring the nature of interprofessional collaboration and family member involvement in an intensive care context. J Interprof Care. 2014;28(1):74-5.

12. Reeves $\mathrm{S}$, Lewin S. Interprofessional collaboration in the hospital: strategies and meanings. J Health Serv Res Policy. 2004;9(4):218-25.

13. Curley $C$, McEachern JE, Speroff T. A firm trial of interdisciplinary rounds on the inpatient medical wards: an intervention designed using continuous quality improvement. Med Care. 1998;36(8 Suppl):AS4-AS12.

14. Priest JR, Bereknyei S, Hooper K, Braddock 3rd CH. Relationships of the location and content of rounds to specialty, institution, patient-census, and team size. PLoS One. 2010:5(6):e11246.

15. Stickrath C, Noble M, Prochazka A, et al. Attending rounds in the current era: what is and is not happening. JAMA Intern Med. 2013;173(12):1084-9.

16. Gonzalo JD, Masters PA, Simons RJ, Chuang $\mathrm{CH}$. Attending rounds and bedside case presentations: medical student and medicine resident experiences and attitudes. Teach Learn Med. 2009;21(2):105-10.

17. Gonzalo JD, Chuang $\mathrm{CH}$, Huang G, Smith $\mathrm{C}$. The return of bedside rounds: an educational intervention. J Gen Intern Med. 2010;25(8):792-8. 
18. Gonzalo JD, Kuperman E, Lehman E, Haidet P. Bedside interprofessional rounds: Perceptions of benefits and barriers by internal medicine nursing staff, attending physicians, and housestaff physicians. J Hosp Med. 2014;9(10):646-51.

19. Gonzalo JD, Heist BS, Duffy BL, et al. Identifying and overcoming the barriers to bedside rounds: a multicenter qualitative study. Acad Med. 2014; 89(2):326-34.

20. Showalter JW, Rafferty CM, Swallow NA, Dasilva KO, Chuang CH. Effect of standardized electronic discharge instructions on post-discharge hospital utilization. J Gen Intern Med. 2011;26(7):718-23.

21. Gonzalo JD, Heist BS, Duffy BL, et al. The art of bedside rounds: a multicenter qualitative study of strategies used by experienced bedside teachers. J Gen Intern Med. 2013;28(3):412-20.

22. Kopp BJ, Mrsan M, Erstad BL, Duby JJ. Cost implications of and potential adverse events prevented by interventions of a critical care pharmacist. Am J Health Syst Pharm. 2007;64(23):2483-7.

23. Gonzalo JD, Heist BS, Duffy BL, et al. The value of bedside rounds: a multicenter qualitative study. Teach Learn Med. 2013;25(4):326-33.

24. Mazzaferri EL. Bedside teaching in the preparation of physicians for the 21st century. Arch Intern Med. 1986;146(10):1912.

25. Peters $\mathrm{M}$, Ten Cate $\mathrm{O}$. Bedside teaching in medical education: a literature review. Perspect Med Educ. 2014;3(2):76-88.

26. Elliot DL, Hickam DH. Attending rounds on in-patient units: differences between medical and non-medical services. Med Educ. 1993;27(6):503-8.

27. Stickrath C, Noble M, Prochazka A, et al. Attending rounds in the current era: What is and is not happening. JAMA Intern Med. 2013;6:1-6.

28. Gonzalo J. The return of bedside rounds. J Gen Intern Med. 2010;25(8):792-8.

29. Bhansali P, Birch S, Campbell JK, et al. A time-motion study of inpatient rounds using a family-centered rounds model. Hosp Pediatr. 2013;3(1):31-8.

30. Stein J. Designing hospital units to optimise outcomes: improving hospital outcomes through teamwork in an accountable care unit. http://www. crepatientsafety.org.au/seminars/designing_hospital_units/ designinghospitalunits-dec11-jasonsteinsession2.pdf. Accessed 29 Aug 2016.

31. O'Mahony S, Mazur E, Charney P, Wang Y, Fine J. Use of multidisciplinary rounds to simultaneously improve quality outcomes, enhance resident education, and shorten length of stay. J Gen Intern Med. 2007;22(8):1073-9.

32. Wild D, Nawaz H, Chan W, Katz DL. Effects of interdisciplinary rounds on length of stay in a telemetry unit. J Public Health Manag Pract. 2004;10(1):63-9.

33. Maguire P. Options for geographic units and multidisciplinary rounds: Tips to streamline workflow and maximize group clout. Hospitalist. 2011. http:// www.todayshospitalist.com/index.php?b=articles_read\&cnt=1254. Accessed 29 Aug 2016.

34. Miller KL, Reeves S, Zwarenstein M, Beales JD, Kenaszchuk C, Conn LG. Nursing emotion work and interprofessional collaboration in general internal medicine wards: a qualitative study. J Adv Nurs. 2008;64(4):332-43.

35. Barrow M, McKimm J, Gasquoine S, Rowe D. Collaborating in healthcare delivery: exploring conceptual differences at the "bedside". J Interprof Care. 2014:4:1-6.

36. Nair BR, Coughlan JL, Hensley MJ. Impediments to bed-side teaching. Med Educ. 1998;32(2):159-62.

37. Porter ME, Lee TH. The strategy that will fix health care. Harvard Bus Rev. 2013;91(12):24.

38. Porter ME, Pabo EA, Lee TH. Redesigning primary care: a strategic vision to improve value by organizing around patients' needs. Health Aff (Millwood). 2013;32(3):516-25.

39. O'Leary KJ, Wayne DB, Landler MP, et al. Impact of localizing physicians to hospital units on nurse-physician communication and agreement on the plan of care. J Gen Intern Med. 2009;24(11):1223-7.

40. Mitchell P, M. Wynia, R. Golden, B. McNellis, S. Okun, CE Webb, V. Rohrbach, IV Kohorn. Core principles \& values of effective team-based health care. Inst Med Discuss Pap. 2012. https://www.nationalahec.org/pdfs/VSRT-TeamBased-Care-Principles-Values.pdf. Accessed 29 Aug 2016.

41. Gittell JH. Coordinating mechanisms in care provider groups: Relational coordination as a mediator and input uncertainty as a moderator of performance effects. Manage Sci. 2002;48(11):1408-26.

42. Schuett MA, Selin SW, Carr DS. Making it work: Keys to successful collaboration in natural resource management. Environ Manag. 2001;27(4):587-93.

43. Jamal TB, Getz D. Collaboration theory and community tourism planning. Ann Tourism Res. 1995;22(1):186-204.

44. Brass DJ, Galaskiewicz J, Greve HR, Tsai WP. Taking stock of networks and organizations: a multilevel perspective. Acad Manage J. 2004;47(6):795-817.
45. Hua Y, Loftness V, Heerwagen JH, Powell KM. Relationship between workplace spatial settings and occupant-perceived support for collaboration. Environ Behav. 2011;43(6):807-26.

46. San Martin-Rodriguez L, Beaulieu MD, D'Amour D, Ferrada-Videla M. The determinants of successful collaboration: a review of theoretical and empirical studies. J Interprof Care. 2005;19 Suppl 1:132-47.

47. Casimiro L, Hall P, Archibald D, Kuziernsky C, Basset-Latulippe A, Varpio L. Barriers and enablers to interprofessional collaboration in health care: Research report. Champlain Region: Academic Health Council; 2011.

48. Prescott PA, Bowen SA. Physician-nurse relationships. Ann Intern Med. 1985; 103(1):127-33.

49. Paradis E, Leslie M, Gropper MA, Aboumatar HJ, Kitto S, Reeves S. Interprofessional care in intensive care settings and the factors that impact it: results from a scoping review of ethnographic studies. J Crit Care. 2013; 28(6):1062-7.

50. Heerwagen JH, Kampschroer K, Powell KM, Loftness V. Collaborative knowledge work environments. Build Res Inf. 2004;32(6):510-28.

51. Nelson EC, Batalden, Paul B., Godfrey, Marjorie M. Quality by design : a clinical microsystems approach. 1st ed. Lebanon, NH, San Francisco: Center for the Evaluative Clinical Sciences at Dartmouth; Jossey-Bass/Wiley; 2007.

52. Gonzalo J, Herzig S, Reynolds E, Yang J. Factors associated with noncompliance during 16-h long call shifts. J Gen Intern Med. 2012;27(11): 1424-31.

53. Gonzalo JD, Yang JJ, Ngo L, Clark A, Reynolds EE, Herzig SJ. Accuracy of residents' retrospective perceptions of $16-\mathrm{h}$ call admitting shift compliance and characteristics. J Grad Med Ed. 2013;5(4):630-3.

\section{Submit your next manuscript to BioMed Central and we will help you at every step:}

- We accept pre-submission inquiries

- Our selector tool helps you to find the most relevant journal

- We provide round the clock customer support

- Convenient online submission

- Thorough peer review

- Inclusion in PubMed and all major indexing services

- Maximum visibility for your research

Submit your manuscript at www.biomedcentral.com/submit
C Biomed Central 